\title{
Visual and Hearing Impairments among Working and Retired Employees with Type 2 Diabetes Mellitus in Two Academic Communities in the Philippines
}

\author{
Angely P. Garcia, RN, MPH, ${ }^{1}$ Shelley Ann F. de la Vega, MD, MSc, ${ }^{1,2}$ \\ Maria Stella T. Giron, MD,PhD ${ }^{1,2}$ and Sarah Jane S. Fabito ${ }^{1}$ \\ ${ }^{1}$ Institute on Aging, National Institutes of Health, University of the Philippines Manila \\ ${ }^{2}$ College of Medicine, University of the Philippines Manila
}

\begin{abstract}
Objectives. 1) To describe the sociodemographic and clinical characteristics of working and retired employees aged 55 years and older; 2) To determine the proportion with visual and hearing impairments in participants with Type 2 diabetes mellitus (T2DM); and 3) To determine the association between quality of life in participants with T2DM and visual and hearing impairments.

Methods. The study utilized a cross-sectional study design - data derived from the findings of the UP Wellness Initiative for Seniors and Elders (UPWISE) Program. The participants were working and retired university employees age 55 years and above residing in urban and rural-urban (rurban) communities. Stratified random sampling was utilized according to working status and sex. Visual and hearing impairments, and the presence of T2DM were assessed using a multidisciplinary diagnostic process, the comprehensive geriatric assessment (CGA).
\end{abstract}

Results. A total of 301 participants agreed to participate and completed the CGA. The mean age of the participants was $64.8( \pm 6.3)$, and $51.2 \%$ belonged to the young-old subgroup. There was an almost equal proportion of males and females while there were more working $(53.8 \%)$ than the retired $(46.2 \%)$. There were $17.6 \%$ of participants with T2DM and of them, $47.2 \%$ with visual impairment $(\mathrm{VI})$ alone, $7.5 \%$ hearing impairment $(\mathrm{HI})$ alone, and $37.7 \%$ with dual sensory impairments (DSI). Good quality of life was reported by $100 \%$ of T2DM participants with $\mathrm{HI}, 80 \%$ with $\mathrm{VI}$, and $72.3 \%$ with DSI. There was no significant association between quality of life and vision and hearing impairments. On the other hand, a significant association was identified between T2DM and DSI ( $p$-value, 0.001).

Conclusion. T2DM and vision and hearing impairments are prevalent among the two academic communities. Visual impairment was more common than hearing impairment. Participants diagnosed with T2DM and having a visual, hearing, or dual sensory impairments reported good quality of life.

Key Words: sensory, geriatric assessments, retired, employees, quality of life, diabetes mellitus

\section{INTRODUCTION}

Corresponding author: Angely P. Garcia, RN, MPH Institute on Aging, National Institutes of Health, University of the Philippines Manila Rm 211, NIH Bldg., UP Manila, 623 Pedro Gil St., Ermita, Manila 1000

Email: apgarcia@up.edu.ph
University employees are also aging. Vision and hearing are the most common senses utilized in their everyday work. As they age and live longer, they may face medical problems and functional disabilities, including sensory impairments. Diabetes is closely linked with several conditions that can impair the senses.

Sensory impairment occurs when one of the senses; sight, hearing, touch, taste, smell, and/or individual awareness is no longer functioning at normal capacity. ${ }^{1}$ The two most commonly encountered sensory impairments 
are visual and hearing. Dual sensory impairment (DSI) is a combination of vision and hearing impairment. The occurrence of DSI is particularly prevalent among the aging population. ${ }^{2}$ According to the World Health Organization (WHO), both impairments have a profound effect on the life of the affected person, their families, and society as a whole. A systematic review of twenty-three studies mostly on community-dwelling adults confirmed the significant association between hearing impairment (HI), visual impairment (VI), DSI, and quality of life. ${ }^{3}$

Sensory impairment is predictive of subsequent functional disability in older persons,${ }^{4}$ and the majority will experience it if they live long enough. ${ }^{5}$ It is estimated that approximately 1.3 billion people live with some form of distance or near vision impairment. ${ }^{6} \mathrm{VI}$ and blindness rank among the major concerns in the country with a current prevalence rate of $1.98 \%$, according to the 2018 Philippine National Blindness Survey and Eye Disease Study conducted by the Philippine Eye Research Institute of the National Institutes of Health. This prevalence represents 1.11 million Filipinos with cataract, 400,000 with an uncorrected error of refraction, almost 300,000 with glaucoma, and 200,000 with maculopathy. Moreover, over 4 million Filipinos are living with undiagnosed eye problems that need to be addressed. ${ }^{7}$

Diabetes is one of the four primary noncommunicable diseases, a lifestyle-related disease, and a chronic condition that occurs when the body cannot effectively use the insulin it produces (also known as Type 2) or does not produce enough insulin (also known as Type 1). ${ }^{8}$ The global prevalence of diabetes is steadily increasing, and in the Western Pacific Region alone, it is estimated that 8.4\% were living with diabetes in $2014 .{ }^{9}$ In the Philippines, the National Nutrition and Health (NNHeS) surveys revealed an increased prevalence of diabetes from $4.6 \%$ in 2003 to $5.2 \%$ in 2008 among adults aged 20 years and above in the country. ${ }^{10,11}$

Diabetes is a significant cause of blindness, kidney failure, heart attacks, stroke, and lower limb amputation ${ }^{12}$ and one of the atherosclerosis-related risk factors in the Philippines. ${ }^{10,11} \mathrm{It}$ is also closely linked with several conditions that can impair vision, in particular, diabetic retinopathy (DR), which an essential cause of blindness and occurs when blood vessels in the retina are damaged. About 3\% of global blindness can be attributed to diabetes. ${ }^{13}$

Little is known about vision and hearing impairments and diabetes among academic employees. Thus, this study sought to determine the proportion of those with vision and hearing impairments among those with Type 2 diabetes mellitus (T2DM) and identify an association between their quality of life and the presence of such specific sensory impairment. This is to generate local evidence that will support policy formulation and establishment of programs that will address the lifestyle (T2DM) and sensory-related problems of aging University employees.

\section{MATERIALS AND METHODS}

This was a cross-sectional study with data derived from Projects 2 and 4 of the UP Wellness Initiative for Seniors and Elders (UPWISE), which aimed to identify the active aging determinants and frailty assessment among the working and retired employees age 55 years and above. Ethics approval was obtained from the UP Manila Review Ethics Board for the conduct of the study.

\section{Study Setting and Participants}

The participants were recruited from one barangay surrounding the Diliman campus in Quezon City, NCR, and seven barangays surrounding the Los Baños campus in Laguna, Region IVA. Participants were faculty and personnel of UP Diliman and Los Baños age 55 years and older, employed or retirees living within the vicinity of the university campuses. A stratified systematic sampling procedure was utilized, with employment status as the primary stratifying variable. Both of the sampling frames used in Diliman and Los Baños were developed from a list of eligible respondents requested from their Human Resource and Development Office (HRDO). These were validated by actual field listing and referrals from co-faculty, barangay office, senior citizens, and church groups. To compute for the minimum required sample size, a 30\% non-response rate in Diliman and 35\% in Los Baños were used.

\section{Data Collection}

\section{Comprehensive Geriatric Assessment (CGA)}

Data were obtained from the CGA, a multidimensional, multidisciplinary diagnostic instrument designed to collect data on the medical, psychosocial, and functional capabilities and limitations in order to uncover medical and functional conditions and risk factors that have not been previously identified and treated. The CGA for communitydwelling Filipinos was developed by the Committee on Aging of the UP-NIH in 2005. It was further refined and internally validated by the Institute on Aging, Philippine College of Geriatric Medicine and Department of Health. This was translated from English to Filipino, pretested, and pilot tested (See Appendix 1).

The study consisted of a health interview and clinical examination using the CGA and laboratory examination. Participants were interviewed regarding the sociodemographic, social, physical, and medical history by trained research assistants who are licensed, health professionals. This was followed by a physical and neurological examination conducted by geriatricians.

\section{Medical Conditions}

VI was assessed using the Jaeger's chart and HI using Rinne's and Weber's tests and otoscopic examination. T2DM was assessed from the clinical evaluation and blood 


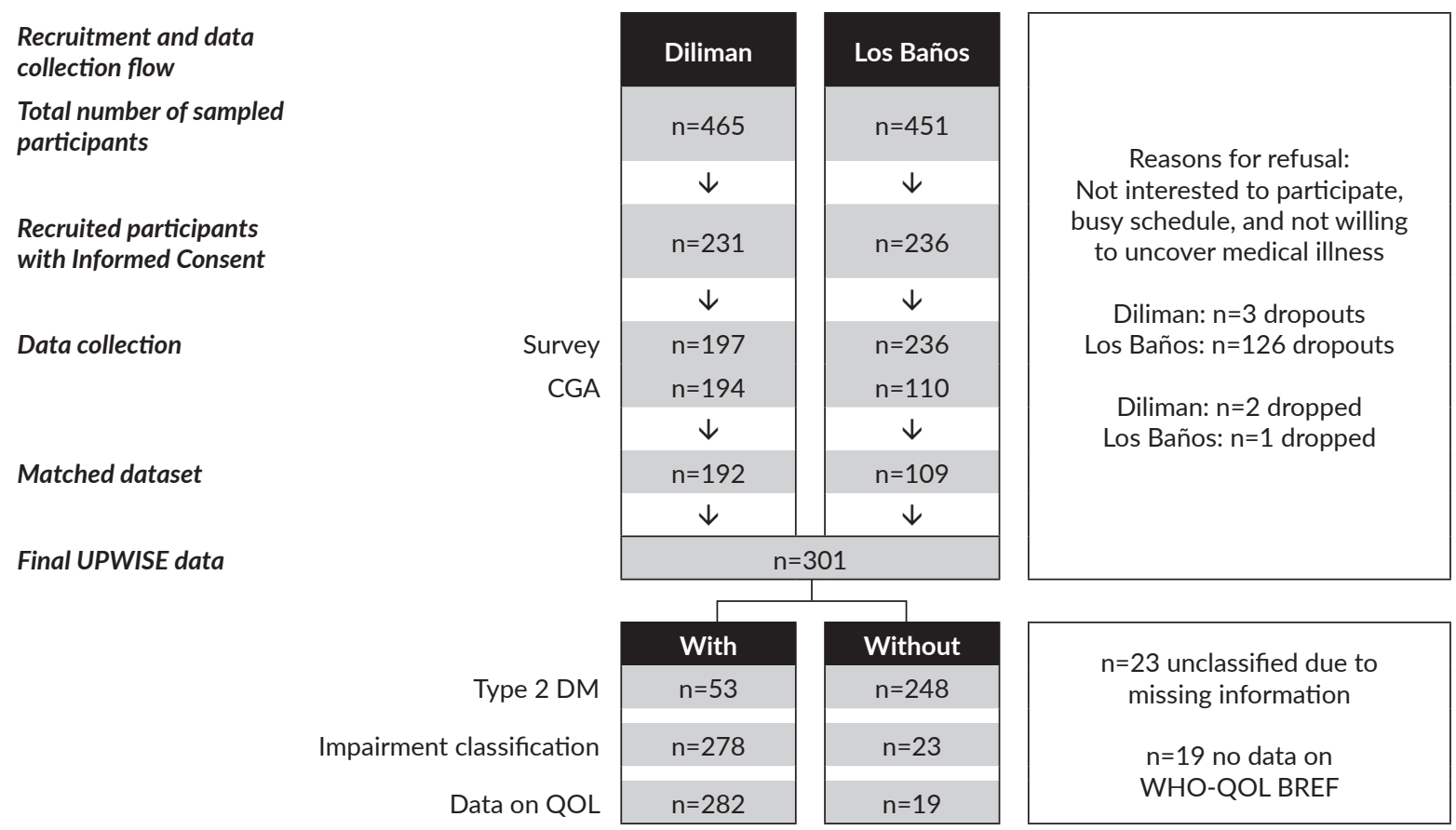

Figure 1. Recruitment and Data Collection Workflow on DM and Sensory Data of UPWISE Program, 2017-2019.

sugar determination. A final diagnosis was made with the agreement of two geriatricians, in case of a disagreement, the diagnosis was obtained from a senior geriatrician.

\section{Quality of Life}

A translated and culturally-validated abbreviated form of the WHO Quality of Life questionnaire (WHOQOL BREF $)^{14}$ was used to assess the quality of life of the participants. The tool is a 27 -item questionnaire which contains the domains of physical health, psychological, social relationships, and environment (See Appendix 2).

\section{Data Analysis}

Descriptive statistics (means, standard deviations, and frequency distributions) were calculated for all continuous and categorical variables measured. Chi-square test, assuming a 5\% level of significance, was used to determine the differences between proportions between T2DM, quality of life, and presence of specific sensory impairment. STATA SE 14 was used to generate and analyze disaggregated data.

\section{RESULTS}

\section{Sociodemographic profile and clinical charac- teristics}

Three hundred one (301) participants agreed to participate in the study. The mean age was $64.8( \pm 6.3)$, range $55-83$ years, $50.2 \%$ were males, and $74.4 \%$ were married. The highest level of education was college, followed by those who had seven (7) years of education in high school. There were slightly more participants with a Master's degree than Ph.D., $19.3 \%$ vs. $16.3 \%$, respectively. Administrative work was the most common type of work among participants, $34.6 \%$ followed by service, for example, maintenance, drivers, $33.6 \%$ (Table 1 ).

Comparing the two campuses, there were no differences in the distribution of age groups, and there were significantly more women in Los Baños. At the same time, there were significantly more men in Diliman, $\mathrm{p}<0.05)$. Los Baños had significantly more $\mathrm{PhDs}$ and Masters and participants who worked in the academe (Table 1).

T2DM was diagnosed with $17.6 \%$ and visual impairment, $50.2 \%$, hearing impairment, $7.3 \%$, and $20.9 \%$ had DSI. Visual impairment and DSI were significantly more common among participants from Diliman, while HI was significantly more common among those from Los Baños. About $68.7 \%$ of participants from both campuses rated their quality of life as good (Table 1).

\section{Vision and hearing impairments in T2DM}

Among T2DM participants, $47.2 \%$ were diagnosed with visual impairment alone, $7.5 \%$ with hearing impairment alone, and $37.7 \%$ with dual sensory impairment. Participants diagnosed with T2DM had a lower proportion of visual impairments than those without T2DM, $55.0 \%$ vs. $47.2 \%$. Participants with T2DM had significantly more dual sensory impairments compared to those without T2DM, $37.7 \%$ vs. $18.2 \%, \mathrm{p}<0.001$ (Table 2).

Among participants with T2DM, visual, hearing, and dual sensory impairments were significantly more common among those who are working compared to those who were retired, $\mathrm{p}<0.05$. On the other hand, among those 
Table 1. Sociodemographic and clinical characteristics of the population, 2017-2019

\begin{tabular}{|c|c|c|c|}
\hline & & Diliman & Los Baños \\
\hline Total & 301 & 192 & 109 \\
\hline & $\%$ & $\%$ & $\%$ \\
\hline Age, mean ( $\pm S D)$ & $64.8( \pm 6.3)$ & $65.5( \pm 6.6)$ & $63.7( \pm 5.8)$ \\
\hline $55-59$ & 24.9 & 23.4 & 27.5 \\
\hline $60-69$ & 51.2 & 47.4 & 57.8 \\
\hline $70-79$ & 23.6 & 29.2 & 13.8 \\
\hline $80+$ & 0.3 & 0.0 & 0.9 \\
\hline \multicolumn{4}{|l|}{ Sex } \\
\hline Female & 49.8 & 43.2 & $61.5^{*}$ \\
\hline Male & 50.2 & 56.8 & 38.5 \\
\hline \multicolumn{4}{|l|}{ Civil status } \\
\hline Single & 8.6 & 8.3 & 9.2 \\
\hline Married & 74.4 & 74.5 & 74.3 \\
\hline Separated / Divorced & 4.0 & 5.2 & 1.8 \\
\hline Widowed & 13.0 & 12.0 & 14.7 \\
\hline \multicolumn{4}{|l|}{ Employment status } \\
\hline Working & 53.8 & 50.0 & 60.6 \\
\hline Retired & 46.2 & 50.0 & 39.4 \\
\hline \multicolumn{4}{|l|}{ Education } \\
\hline High school or less & 27.9 & 31.3 & 22.0 \\
\hline Post-secondary/vocational & 7.6 & 9.9 & 3.7 \\
\hline College & 28.9 & 33.9 & 20.2 \\
\hline MS & 19.3 & 16.7 & 23.9 \\
\hline $\mathrm{PhD} /$ postdoctoral & 16.3 & 8.3 & $30.3^{* *}$ \\
\hline \multicolumn{4}{|l|}{ Type of Work } \\
\hline Administration & 34.6 & 36.5 & 31.2 \\
\hline Service & 33.6 & 37.5 & 26.6 \\
\hline Academe & 30.9 & 25.5 & $40.4^{*}$ \\
\hline Health-related & 0.7 & 0.5 & 0.9 \\
\hline \multicolumn{4}{|l|}{ Medical condition } \\
\hline Type 2 Diabetes mellitus & 17.6 & 21.6 & 15.7 \\
\hline Visual impairment & 50.2 & 40.6 & $67.0^{* * *}$ \\
\hline Hearing impairment & 7.3 & 10.4 & $1.8^{* *}$ \\
\hline Dual sensory impairment & 20.9 & 26.6 & $11.0^{* *}$ \\
\hline \multicolumn{4}{|l|}{ Quality of life } \\
\hline Poor & 0.4 & 0.6 & 0.0 \\
\hline Moderate & 31.0 & 35.2 & 23.7 \\
\hline Good & 68.7 & 64.2 & 76.3 \\
\hline
\end{tabular}

Dual sensory impairment - presence of visual and hearing impairments. ${ }^{*} p<0.05,{ }^{* *} p<0.01,{ }^{* * *} p<0.001$
Table 2. Visual and hearing impairments among participants with T2DM, 2017-2019

\begin{tabular}{lcc} 
& $\begin{array}{c}\text { With T2DM } \\
\%\end{array}$ & $\begin{array}{c}\text { Without T2DM } \\
\%\end{array}$ \\
\hline Visual impairment & 47.2 & 55.0 \\
Hearing impairment & 7.5 & 7.7 \\
Dual sensory impairment & 37.7 & $18.2^{* *}$ \\
\hline
\end{tabular}

${ }^{* *} p<0.001$

Table 2a. Visual and hearing impairments among participants with T2DM, 2017-2019

\begin{tabular}{lccccc} 
& \multicolumn{2}{c}{ With T2DM } & & \multicolumn{2}{c}{ Without T2DM } \\
\cline { 2 - 3 } \cline { 5 - 6 } & $\begin{array}{c}\text { Working } \\
\text { \% }\end{array}$ & $\begin{array}{c}\text { Retired } \\
\text { Visual impairment }\end{array}$ & & $\begin{array}{c}\text { Working } \\
\%\end{array}$ & $\begin{array}{c}\text { Retired } \\
\%\end{array}$ \\
Hearing impairment & $37.0^{*}$ & 57.7 & & 57.4 & 52.0 \\
Dual sensory impairment & $14.8^{*}$ & 0.0 & 3.3 & $13.3^{*}$ \\
\hline
\end{tabular}

${ }^{*} p<0.05$

without T2DM, hearing impairment was significantly more common among retired participants, $\mathrm{p}<0.05$ (Table 2a).

\section{Association of quality of life and T2DM and vision, and hearing impairments}

One hundred percent of T2DM participants with hearing impairment, $80 \%$ with visual impairment, and $72.2 \%$ with dual sensory impairment reported good quality of life. There were no differences in the quality of life between those with any impairment and T2DM (Table 3).

\section{DISCUSSION AND CONCLUSION}

The mean age (64.8 years) of the study participants is relatively near the age of compulsory retirement age (65 years) in the country. In terms of the distribution of age groups, there were no differences on both campuses. Studies across countries found that age is one of the associated factors in the prevalence of VI among diabetics globally. ${ }^{15-23}$ These studies reported that among people with diabetes, the prevalence of VI ranged from $1.4 \%$ to $42.0 \%$ and increased with age. $\mathrm{HI}$ is also considered as one of the most prevalent age-related health conditions. ${ }^{24-26}$ Findings from the Global Burden of Disease revealed that both hearing and vision impairment had been recognized as essential contributors to nonfatal disease burden, particularly among older

Table 3. Quality of life among participants with T2DM and visual and hearing impairments, 2017-2019

\begin{tabular}{|c|c|c|c|c|c|c|}
\hline \multirow[b]{2}{*}{ QOL } & \multicolumn{3}{|c|}{ With T2DM } & \multicolumn{3}{|c|}{ Without T2DM } \\
\hline & $\begin{array}{c}\text { Visual } \\
\text { impairment } \\
\%\end{array}$ & $\begin{array}{c}\text { Hearing } \\
\text { impairment } \\
\%\end{array}$ & $\begin{array}{c}\text { Dual sensory } \\
\text { impairment } \\
\%\end{array}$ & $\begin{array}{c}\text { Visual } \\
\text { impairment } \\
\%\end{array}$ & $\begin{array}{c}\text { Hearing } \\
\text { impairment } \\
\%\end{array}$ & $\begin{array}{c}\text { Dual sensory } \\
\text { impairment } \\
\%\end{array}$ \\
\hline Poor & 0.0 & 0.0 & 0.0 & 0.9 & 0.0 & 0.0 \\
\hline Moderate & 20.0 & 0.0 & 27.8 & 37.4 & 20.0 & 44.4 \\
\hline Good & 80.0 & 100.0 & 72.2 & 61.7 & 80.0 & 55.6 \\
\hline
\end{tabular}


adults. ${ }^{27} \mathrm{~A}$ study on estimated years lived with and without age-related sensory impairments found VI and $\mathrm{HI}$ affect older adults for substantial periods of their remaining life. ${ }^{28}$

Diabetes is one of the significant public health concerns worldwide, and it represents a leading cause of VI in individuals in many countries. ${ }^{15-23}$ Almost $20 \%$ of the UPWISE participants had T2DM. There was a higher prevalence of diabetes in this group compared to the national data $(17.6 \%$ geriatrician-diagnosed vs. $5.2 \%$ FBG and history $)^{10}$ Those with diabetes have a higher risk of cardiovascular disease, kidney disease, vision problems, neurological deficits, musculoskeletal problems, and mental health alterations compared to employees without the condition. ${ }^{29}$ People with diabetes were more likely to have uncorrectable VI than those without diabetes, and vision loss is more common in people with the condition than those without. ${ }^{30}$ Diabetes was also found to be positively associated with hearing loss in the HealthABC study. ${ }^{31}$ Furthermore, both diabetes and occupational status are associated with significantly elevated risk for early retirement as people who develop T2DM are also vulnerable to other risk factors that could directly or indirectly lead to a premature exit from the workforce. ${ }^{32}$

In terms of the composition of participants, males and females in this study were almost equal in proportion. A study on global sensory impairments in older adults in the US found that older adults, men, African Americans, and Hispanics had greater multisensory impairments. ${ }^{33}$ However, studies among the Canadian diabetic population ${ }^{18}$ found female sex as associated with VI and one of the risk factors for visual disability among diabetic Central Africans. ${ }^{21}$ Similar findings in a study on the prevalence of VI among the diabetic population where a higher proportion of visually impaired females than males with no overall ethnic differences was reported. ${ }^{34}$ Estimating years lived with impairments, men and women were predicted to have a similar proportion of life with HI, VI, or DSI. ${ }^{27}$

With regards to the relationship between diabetes and occupation, in the US, it is estimated that $8.1 \%$ of all workingage adults, 18 to 64 years old, have diabetes. ${ }^{35} \mathrm{~A}$ study among academic health center employees with diabetes revealed that workers with diabetes experience a high prevalence of work limitations and have a higher likelihood of work limitations when they are sicker. ${ }^{36}$ These work limitations include physical, psychosocial, environmental, and output limitations. A study examined the relative rates of disability retirement among employees in Denmark over ten years and highlighted that the risk of disability retirement increases as occupational status decreases. ${ }^{32}$ Their results showed that diabetes and low occupational status also have an apparent compound effect. Workers in elementary occupations have a $1,173 \%$ greater risk for early retirement than professionals without diabetes. Furthermore, a case-control study among people with diabetes in Central Africa reported low education level and rural-urban migration to be the critical, independent determinants of visual disability (blindness and visual impairment). ${ }^{16}$

In UPWISE, administrative work was the most common, followed by service type of work. Looking at the detailed occupational profile of the participants, administrative type includes those non-teaching staff such as office assistants, administrative officers, administrators, or officials. In contrast, the service type includes maintenance and housekeeping personnel, security, drivers, and personnel in charge of food service. ${ }^{37}$

Given that administrative and service type of work are lower occupations compared to academe or professionals, the risk of visual disability and early retirement is more likely in these groups.

The majority of the participants were married. In terms of educational status, they had higher educational attainment compared to the 2018 Longitudinal Study on Ageing and Health in the Philippines (LSAHP), the first nationally representative longitudinal study on aging based on the proportion of those who had a college degree or higher (66.5\% vs. $7.9 \%){ }^{38} \mathrm{~A}$ higher proportion of participants with postgraduate studies can be attributed to their nature of work. Given that both sites are academic communities, pursuance of postgraduate studies is required for merit promotions, career advancement, and professional growth. Los Baños had significantly more participants who had postgraduate studies who worked in the academe. This can be attributed to the proportion of sampled participants in this site where the majority were females and working under academe type of work, including faculty and Research Extension and Professional Staff (REPS). On the other hand, Diliman had more service type of workers, who were mostly males. ${ }^{37}$

Overall clinical characteristics showed that aside from T2DM, UPWISE participants had VI, DSI, and $\mathrm{HI}$, wherein VI and DSI were significantly more common among participants from Diliman. HI was significantly more common among those from Los Baños. This can be attributed to the participant's characteristics, existing medical conditions, occupational environment, and risk factors associated with VI, HI, and DSI. Age, sex, race were the factors most strongly associated with hearing loss in the US. ${ }^{39}$ At the same time, male, tinnitus, dizziness, and occupational noise exposure were reported as most strongly associated with hearing loss among Korean elders. ${ }^{40}$ The urban setting in Diliman and the rurban setting in Los Baños might be a factor in the occurrence of VI, HI, and DSI; however, this warrants further investigation.

Of those participants with T2DM, the majority had VI alone, followed by those with DSI and HI alone. Age was the most notable predictor of continued visual loss after diabetes diagnosis based on a comprehensive assessment of predictors of VI. ${ }^{22}$ Studies have shown that VI among diabetics is associated with various factors and conditions such as body mass index,${ }^{15}$ cardiovascular diseases,${ }^{15}$ duration of diabetes, ${ }^{15,18,21,23,41}$ diabetic retinopathy (DR), ${ }^{19,21,23,38}$ 
Visual and Hearing Impairments among Employees with T2DM in Two Academic Communities

blindness, ${ }^{39}$ and other eye conditions such as cataract, ${ }^{15,22-23,39}$ age-related macular degeneration (ARMD), ${ }^{22,42}$ retinal detachment, ${ }^{15,43}$ optic atrophy, ${ }^{39}$ glaucoma, ${ }^{15,21}$ and macular edema. ${ }^{15,21,23}$ These studies reported a prevalence of VI among people with diabetes ranging from $1.4 \%$ to $42.0 \%$. Compare to these studies, UPWISE participants had a higher prevalence of VI. Both VI and T2DM had a higher prevalence than the national data, and being an academic community could be attributed to some extent.

This study found a significant association between T2DM and dual sensory impairment. Older adults with vision loss may be more likely also to have hearing loss, and the opposite appears correct as well. ${ }^{44} \mathrm{~A}$ study suggested that sensory impairments could share common risk factors or biologic aging markers. ${ }^{45}$ Similar to T2DM, DSI prevalence increases with age, ${ }^{46}$ and studies have shown that it confers additional burden over and above the effects of a single sensory impairment. ${ }^{47}$ The result of the UPWISE study regarding the occurrence of DSI among those with T2DM was slightly higher than those studies showing between $9 \%$ and $21 \%$ of adults older than 70 years having some degree of DSI. ${ }^{2}$ In contrast, a study revealed an association between age-related maculopathy and hearing loss was stronger at younger ages $\left(<70\right.$ years).$^{45}$

In terms of clinical characteristics, aside from T2DM, VI, and HI, noncommunicable diseases also dominated the top geriatrician's diagnoses, including hypertension and dyslipidemia. ${ }^{23}$ These are consistent with the atherosclerosis-related diseases and risk factors identified by the NNHeS. ${ }^{10,11}$ These diseases and risk factors can be attributed to the nature of work and stress in the academe, continuing changes in lifestyle associated with urbanization, and industrialization, which eventually lead to unhealthy diet and physical inactivity specifically on those who do an administrative type of work, mostly working and females. ${ }^{23}$ Furthermore, presbyopia, EOR, cataract, ARMD, and vertigo were among the top 5 specific sensory problems of the UPWISE participants, 4 of which were affecting the vision. Compared to the 2017 national data, the UPWISE had a lower proportion in terms of diagnosed cataract (10.3\% vs. $33 \%)$ and glaucoma $(1.7 \%$ vs. $14 \%)$ while had a higher proportion in terms of $\operatorname{EOR}(39.2 \%$ vs. $33 \%){ }^{48}$

VI and age-related ophthalmic diseases affect economic and educational opportunities. ${ }^{49}$ This also supports the strong association between VI and older age, members of racial/ethnic minorities, lower-income, and lack of health insurance, all independent of diabetes status in the US using the National Health and Nutrition Examination Surveys. ${ }^{23}$ However, a study found that VI is associated with even higher odds of not working among women, participants younger than 55 years, and diabetic individuals. ${ }^{50}$ The risk of visual disability is four times higher in patients with DR and two times higher in females with DM. ${ }^{21}$ DR remains the most important preventable cause of VI in the working-age population in many countries. ${ }^{51,52}$
Exploratory qualitative research revealed that those patients who had not experienced other complications of diabetes, the threat of vision loss, was the most devastating. ${ }^{53}$ Poor vision among older adults can lead to physical decline and cognitive problems. ${ }^{44,54} \mathrm{~A}$ study confirmed that there is a strong link between hearing status and the risk of disability, dementia, and depression. ${ }^{55}$ Individuals with DSI experience higher rates of adverse events across many healthrelated outcomes such as cognitive impairment, functional dependence, and worse outcomes. ${ }^{56}$

VI is associated with self-rated health, ${ }^{18}$ reduces the quality of life,,${ }^{57}$ declines in well-being, ${ }^{58}$ and health-related quality of life (HRQL). ${ }^{59}$ In contrast, $\mathrm{HI}$ is associated with loneliness and depression, ${ }^{60}$ physical disability, ${ }^{61}$ communication difficulties, reduced levels of activity participation, ${ }^{62}$ and lower quality of life. ${ }^{63}$ Furthermore, vision loss and hearing loss have each been shown to be associated with depression, social isolation, anxiety, paranoia, and decreased self-esteem. ${ }^{64-66}$ They have also been shown to have a negative effect on intimate relationships ${ }^{67}$ and can result in poor self-efficacy in the workplace. ${ }^{68}$ Older adults with hearing loss living in rural communities will face more isolation than adults with hearing loss living in urban settings. ${ }^{69}$ On the other hand, compare to VI and $\mathrm{HI}$ alone, DSI has been shown to have psychological, psychosocial, and functional effects and is associated with depression or depressive symptoms. ${ }^{2}$

Individuals with DSI had greater odds of experiencing symptoms of depression ${ }^{70}$ and cognitive decline and functional decline ${ }^{71}$ compared to those with single sensory and no sensory impairment. To summarize, evidence showed that sensory impairments affect various aspects of wellbeing, including physical, psychological, psychosocial, and occupational wellbeing. The UPWISE found no differences in the quality of life between those with any impairment and T2DM.

Findings from the UPWISE study showed that the majority had a good quality of life. This is consistent with the findings of a study focusing on older Filipino university instructors reporting life satisfaction and high psychological resilience when faced with both work-related and family stressors. ${ }^{72}$ Furthermore, the study highlighted that although workers faced stressful experiences in the workplace and at home, resources such as prayer and social support, aided them in coping with those perceived stressors.

Age, marital status, and education were found to be significantly associated with successful aging in the Philippines. ${ }^{73}$ LSAHP revealed that the young-old have better self-rated health than the middle (70-79) and oldestold $(80+) .{ }^{24}$ Most of the UPWISE participants belonged to the young-old subgroup, had higher educational attainment, and had a good quality of life regardless of the presence or absence of T2DM and sensory impairments. Given that this particular group belonged to the young-old subgroup, most were married, and with higher educational attainment 
compared to the general population, they are more likely to age successfully. However, considering the presence of sensory impairments and other health determinants, concluding that academic communities are aging more successfully, actively, or healthier than the general population warrants further investigation.

A population-based cohort study among T2DM highlighted the importance of eliminating barriers to efficient eye care by increasing patients' and primary care practitioners' awareness of the necessity of regular eye examinations and timely surgical treatment. ${ }^{13}$ Furthermore, the results of a 4-year follow up study on self-reported sensory impairments and psychosocial health using the English Longitudinal Study of Ageing stressed the importance of identifying and addressing sensory impairments in older adults to improve their health and well-being. ${ }^{74}$ According to a situational analysis of current services and programs for age-related VI in the Philippines in 2016, VI is often not discussed, and eye health is rarely focused in terms of health promotion at the barangay and municipal levels. Only a few provide specific services for eye health, such as screening and eye examinations. Targeting this age group is an opportunity to improve the effectiveness of existing efforts on eye health, provided that the vast majority of preventable visual impairment appears in people aged 50 years and above. ${ }^{75}$

Vision loss is more common in people with diabetes than in people without the condition. Thus it is recommended that diverse public health strategies are needed to reduce the burden of both correctable and uncorrectable VI. ${ }^{76}$ Evidence showed that VI and hearing loss was significantly associated with an increased risk of mortality ${ }^{4,64,77-78}$ hospitalizations, and readmissions, ${ }^{2}$ the association is mediated, or at least explained, by other factors. ${ }^{64,79}$ The risk of premature mortality appears to be more pronounced for DSI compared with single sensory impairment. ${ }^{80-81}$ In contrast, the risk of mortality is higher among participants with one or two or more sensory impairments than those without sensory impairments. ${ }^{82}$

Studies on population-based and rural communities also revealed that sensory impairments are predictors of decreased survival, independent of other traditional mortality risk factors such as hypertension and diabetes. ${ }^{80,83}$ Untreated sensory loss can cause an increased risk for falls, isolation, depression, anxiety, and dependence on others. Screening and treatment can significantly reduce the incidence of VI due to diabetes ${ }^{15}$. Health education, early diagnosis as well as treatment of DR and other diseases will mainly alleviate these ocular morbidities. ${ }^{17}$ With an aging workforce and increasing prevalence of diabetes, it is crucial to target primary ${ }^{76}$, secondary and tertiary prevention to the groups that need it most to prevent diabetes and its co-morbid conditions even before their occurrence and prolong the working lives of individuals. ${ }^{22}$

\section{CONCLUSION}

T2DM and vision and hearing impairments are prevalent among the two academic communities. Among those with T2DM, the majority had vision impairment alone, followed by those with dual sensory and hearing impairment. Findings from the UPWISE study call for action to prevent worse outcomes associated with these impairments and to address the needs of the aging University employees and retirees.

\section{Recommendations}

It is necessary to address the vision and hearing impairments and diabetes to maintain health, reduce workforce limitations, ensure workforce productivity, and improve quality of life. Thus, the following are recommendations from the study; a.) being in an academic community, empower working and retired employees to take a proactive role in promoting a healthy lifestyle and eye and ear health, b.) ensure access to eye and ear health services through a comprehensive service package (prevention, visual and hearing screening, early treatment, intervention, and rehabilitation) not only for the working but also for the retired ones, c.) improve communication strategies with persons experiencing vision and hearing impairments, d.) conduct targeted and tailor-fit activities which will build synergies between healthy aging and health promotion in the workplace through a comprehensive workplace promotion program, and e.) conduct of further research on the monitoring of sensory impairments among employees and retirees and interventions and its effect to functional ability and quality of life.

\section{Study limitations}

The limitations of the study were the drop-out and attrition rates, specifically in the rurban site. Moreover, separate analysis for right and left eyes and ears was not conducted in this study. More studies among those with diabetes and sensory impairment and the impact on participant's functional ability, social interaction, and access to health are recommended.

\section{Acknowledgments}

Project Research Assistants: Hannah M. Pellejo, Francis Michael Torreblance, Maika Louise Bugante, Lizza May Nava, Dana Lorena Tanuecoz, and Emmanuel Tangco

$\mathrm{NIH}$ Administrative Assistants: Eselbless Angelica Ambe and Cristopher Naguit

Program Managers Dr. Grace Cruz and Dr. Myles Benigno

Statisticians: Dr. Ma. Lourdes Amarillo, Mr. Michael Dominic Del Mundo, and Mr. Leo Angelo Ocampo

UP VPAA Dr. Ma. Cynthia Rose B. Bautista

EIDR AVP Dr. Carla Dimalanta

EIDR Staff Ms. Grace Reytas

UP Manila Chancellor Carmencita Padilla 
UP Manila VC Arlene Samaniego

NIH UP Manila Executive Director Eva C De la Paz NIH UP Manila Deputy ED Dr. Carmela Lapitan UP Manila ERB

UP Manila RGAO Ms. Kashe Ty and Ms. Vivian Viala

UP Manila Research Grants and Development Office

UP Manila Accounting

UP Diliman Chancellor Michael Tan

UP Diliman Health Service Director Dr. Jesusa Catabui

International Collaborator

Robert Cumming, MBBS NSW MPH Sydney Ph.D. Sydney

The University of Sydney NSW Australia

\section{Statement of Authorship}

All authors participated in data collection and analysis, and approved the final version submitted.

\section{Author Disclosure}

All authors declared no conflicts of interest.

\section{Funding Source}

The study was funded by the Emerging Interdisciplinary Research Program of the Office of the Vice President for Academic Affairs, University of the Philippines.

\section{REFERENCES}

1. World Health Organization. Prevention of Blindness and Deafness [Internet]. 2019 [cited 2019 December]. Available from: https://www. who.int/pbd/en/

2. Saunders GH, Echt KV. An overview of dual sensory impairment in older adults: perspectives for rehabilitation. Trends Amplif. 2007 Dec;11(4):243-58. doi: 10.1177/1084713807308365

3. Tseng YC, Lui HS, Lou MF, Huang GS. Quality of Life in older adults with sensory impairments: a systematic review. Qual Life Res. 2018 Aug;27(8):1957-1971. doi: 10.1007/s11136-018-1799-2.

4. Reuben DB, Mui S, Damesyn M, Moore AA, Greendale GA. The Prognostic Value of Sensory Impairment in Older Persons. J Am Geriatr Soc. 1999 Aug;47(8):930-5. doi: 10.1111/j.1532-5415. 1999.tb01286.x.

5. Schubert CR, Fischer ME, Pinto AA, Klein BEK, Klein R, Tweed TS, et al. Sensory Impairments and Risk of Mortality in Older Adults. J Gerontol A Biol Sci Med Sci. 2017 May 1;72(5):710-715. doi: $10.1093 /$ gerona/glw036.

6. World Health Organization. Key Facts - Blindness and vision impairment [Internet]. 2019 October 8 [cited 2019 Dec]. Available from https://www.who.int/news-room/fact-sheets/detail/blindnessand-visual-impairment.

7. Department of Health. Eye Health Services Part of the Universal Health Care. [Internet], 2019 [cited Nov 2019]. Available from https:// www.doh.gov.ph/press-release/eye-health-services-part-of-universalhealth-care-DOH

8. World Health Organization. Noncommunicable diseases-Diabetes [Internet]. 2019 [cited Dec 2019]. Available from http://www. emro.who.int/noncommunicable-diseases/diabetes/index.html

9. World Health Organization. Health Topics-Diabetes [Internet]. 2019 [cited Dec 2019]. Available from https://www.who.int/westernpacific/ health-topics/diabetes.

10. Paz-Pacheco E, Velandria FV, Villarruz MV, Roxas A, Sy RA, Morales DD, Amarillo L, Abola MTB, Punzalan FE, Dans AL (2005). National Nutrition And Health Survey (NNHeS): Atherosclerosis - related diseases and risk factors. Philippine Journal of Internal Medicine, 43(3), 103-115.

11. Sy RG, Morales DD, Dans AL et al. J Epidemiol. 2012; 22(5): 440447. Published online 2012 Sep 5. Prepublished online 2012 Jul 14. doi: 10.2188/jea.JE20110095.

12. World Health Organization. Key Facts - Diabetes [Internet]. 2018 October 30 [cited Dec 2019]. Available from https://www.who.int/ en/news-room/fact-sheets/detail/diabetes.

13. Bourne RRA, Stevens GA, White RA Smith JL, Flaxman SR, Price H et al. Causes of vision loss worldwide, 1990-2010: a systematic analysis. Lancet Glob Health. 2013 Dec;1(6):e339-49. doi: 10.1016/S2214109X(13)70113-X. Epub 2013 Nov 11.

14. De la Vega SF. Cultural Validation of the WHOQOL-BREF in ambulatory community-dwelling Filipino older persons. Philippine Journal of Health Research and Development. 2013 Dec; 17 (1): 8-25.

15. Kahloun R, Jelliti B, Zaouali S, Attia S, Ben Yahia S, et al. Prevalence and causes of visual impairment in diabetic patients in Tunisia, North Africa. Eye (Lond). 2014 Aug;28(8):986-91. doi: 10.1038/ eye.2014.131. Epub 2014 Jun 13.

16. Longo-Mbenza B, Muaka MM, Yokobo EC, Phemba IL, Mokondjimobe E, Gombet T, et al. Effects of biomarkers of oxidative stress damage on prevalence and severity of visual disability among black Central Africans. Mol Vis. 2012;18:1619-28. Epub 2012 Jun 19.

17. Laatikainen L, Ojamo M, Rudanko SL, Summanen P, KeinänenKiukaanniemi S, Tuomilehto J et al. Improving visual prognosis of the diabetic patients during the past 30 years based on the data of the Finnish Register of Visual Impairment. Acta Ophthalmologica, 2016. 94(3), 226-231. doi: 10.1111/aos.12952. Epub 2016 Feb 29.

18. Hwang J, Rudnisky C, Bowen S, Johnson JA. Socioeconomic factors associated with visual impairment and ophthalmic care utilization in patients with type II diabetes. Can J Ophthalmol. 2015 Apr;50(2):119-26. doi: 10.1016/j.jcjo.2014.11.014.

19. Al-Till MI, Al-Bdour MD, Ajlouni KM. Prevalence of blindness and visual impairment among Jordanian diabetics. Eur J Ophthalmol. 2005 Jan-Feb;15(1):62-8.

20. Khandekar R, Mohammed AJ. Visual disabilities among diabetics in Oman. Saudi Med J. 2005 May;26(5):836-41.

21. Muaka MM, Longo-Mbenza B. Causes of visual disability among Central Africans with diabetes mellitus. Afr Health Sci. 2012 Jun; 12(2): 193-197. doi: 10.4314/ahs.v12i2.18.

22. de Fine Olivarius N, Siersma V, Almind GJ, Nielsen NV. Prevalence and progression of visual impairment in patients newly diagnosed with clinical type 2 diabetes: a 6-year follow up study. BMC Public Health. 2011; 11: 80. Published online 2011 Feb 4. doi: 10.1186/14712458-11-80.

23. Klein R, Klein BEK, Moss SE. Visual Impairment in Diabetes. Ophthalmology, 1984. Jan;91(1):1-9.

24. Kiely KM, Gopinath B, Mitchell P, Browning CJ, Anstey KJ. Evaluating a dichotomized measure of self-reported hearing loss against gold standard audiometry: prevalence estimates and age bias in a pooled national data set. J Aging Health. 2012 Apr; 24(3):439-58. doi: 10.1177/0898264311425088. Epub 2011 Dec 28.

25. Lin FR, Thorpe R, Gordon-Salant S, Ferrucci L. Hearing loss prevalence and risk factors among older adults in the United States. J Gerontol A Biol Sci Med Sci. 2011 May;66(5):582-90. doi: 10.1093/gerona/glr002. Epub 2011 Feb 27.

26. Cruickshanks KJ, Wiley TL, Tweed TS, et al. Prevalence of hearing loss in older adults in Beaver Dam, Wisconsin. The Epidemiology of Hearing Loss Study. Am J Epidemiol. 1998 Nov 1;148(9):879-86.

27. Vos T, Flaxman AD, Naghavi M, et al. Years lived with disability (YLDs) for 1160 sequelae of 289 diseases and injuries 1990-2010: a systematic analysis for the Global Burden of Disease Study 2010. Lancet. 2012 Dec 15;380(9859):2163-96. doi: 10.1016/S01406736(12)61729-2.

28. Kiely KM, Mitchell P, Gopinath B, Luszcz MA, Jagger C, Anstey KJ. Estimating the Years Lived With and Without Age-Related Sensory Impairment. J Gerontol A Biol Sci Med Sci. 2016 May;71(5):637-42. doi: 10.1093/gerona/glv198. Epub 2015 Oct 29. 
Visual and Hearing Impairments among Employees with T2DM in Two Academic Communities

29. American Diabetes Association. Standards of medical care in diabetes--2010. Diabetes Care. 2010 Jan;33 Suppl 1(Suppl 1):S1161. doi: 10.2337/dc10-S011. Erratum in: Diabetes Care. 2010 Mar;33(3):692.

30. Zhang X, Gregg EW, Cheng YJ, et al. Diabetes Mellitus and Visual Impairment: National Health and Nutrition Examination Survey, 1999-2004. Arch Ophthalmol. 2008 Oct;126(10):1421-7. doi: 10.1001/archopht.126.10.1421.

31. Helzner EP, Cauley JA, Pratt SR, Wisniewski SR, Zmuda JM, Talbott $\mathrm{EO}$ et al. Race and Sex Differences in Age-Related Hearing Loss: The Health, Aging and Body Composition Study. J Am Geriatr Soc. 2005 Dec; 53(12):2119-27.

32. Cleal B, Poulsen K, Hannerz H, Andersen LL. A prospective study of occupational status and disability retirement among employees with diabetes in Denmark. Eur J Public Health. 2015 Aug;25(4):617-9. doi: 10.1093/eurpub/cku240. Epub 2015 Feb 9.

33. Correia C, Lopez KJ, Wroblewski KE, Huisingh-Scheetz M, Kern DW, Chen RC, Schumm LP, Dale W, McClintock MK, Pinto JM. Global Sensory Impairment in Older Adults in the United States. J Am Geriatr Soc. 2016 Feb;64(2):306-313. doi: 10.1111/ jgs.13955.

34. Hayward LM, Burden ML, Burden AC, Blackledge H, Raymond NT, Botha JL et al. What is the prevalence of visual impairment in the general and diabetic populations: are there ethnic and gender differences? Diabet Med. 2002 Jan;19(1):27-34.

35. Centers for Disease Control and Prevention. National diabetes fact sheet: General information and national estimates on diabetes in the United States. Atlanta, GA: [Internet]. 2011 [cited April 2020]. Available from https://www.cdc.gov/diabetes/pubs/pdf/methods11.pdf

36. Sylvia ML, Weiner JP, Nolan MT, Han HR, Brancati F, White $\mathrm{K}$. Work limitations and their relationship to morbidity burden among academic health center employees with diabetes. Workplace Health Saf. 2012 Oct;60(10):425-34. doi: 10.3928/2165079920120917-38.Epub2012 Sep24.DOI:10.1177/216507991206001004.

37. De la Vega SF. University of the Philippines Wellness Initiative for Seniors and Elderly (UPWISE) Program 2016-2019 Final Report. Institute on Aging, NH UP Manila. Forthcoming 2020.

38. Cruz, G. T. (2019). 'Introduction', in G. T. Cruz, C. J. P. Cruz, and Y. Saito (eds.), Ageing and Health in the Philippines. Jakarta, Indonesia: Economic Research Institute for ASEAN and East Asia, pp. 1-12.

39. Lin FR, Thorpe R, Gordon-Salant S, Ferrucci L. Hearing Loss Prevalence and Risk Factors Among Older Adults in the United States. J Gerontol A Biol Sci Med Sci. 2011 May;66(5):582-90. doi: 10.1093/gerona/glr002. Epub 2011 Feb 27.

40. Kim JS. Prevalence and factors associated with hearing loss and hearing aid use in korean elders. Iran J Public Health. 2015 Mar;44(3):308-17.

41. Bamashmus MA, Gunaid AA, Khandekar RB. Diabetic retinopathy, visual impairment and ocular status among patients with diabetes mellitus in Yemen: a hospital-based study. Indian J Ophthalmol. 2009 Jul-Aug; 57(4): 293-298. doi: 10.4103/0301-4738.53055.

42. Singalavanija A, Luangsawang K, Chotikavanich S, Tanterdtham J, Samsen P. Causes of visual impairment in Thai diabetic patients in the visual rehabilitation clinic. J Med Assoc Thai 2012 Apr;95 Suppl 4:S24-9.

43. Shah S. Blindness and visual impairment due to retinal diseases. Community Eye Health. 2009 Mar;22(69):8-9.

44. JAMA and Archives Journals. (2006, October 11). Vision And Hearing Loss Often Occur Together In Older Age. Science Daily. Retrieved April 17, 2020 from www.sciencedaily.com/ releases/2006/10/061010022657.htm.

45. Chia EM, Mitchell P, Rochtchina E, Foran S, Golding M, Wang JJ. Association Between Vision and Hearing Impairments and Their Combined Effects on Quality of Life. Arch Ophthalmol. 2006 Oct;124(10):1465-70.

46. Jee J, Wang JJ, Rose KA, Lindley R, Landau P, Mitchell P. Vision and hearing impairment in aged care clients. Ophthalmic Epidemiol. 2005 Jun;12(3):199-205.

47. Kiely KM, Anstey KJ, Luszcz MA. Dual sensory loss and depressive symptoms: the importance of hearing, daily functioning and activity engagement. Front Hum Neurosci. 2013 Dec 16;7:837. doi: 10.3389/ fnhum.2013.00837. eCollection 2013.

48. Department of Health. Prevention and Blindness Program [Internet]. [cited Dec 2019]. Available from https://www.doh.gov.ph/nationalprevention-of-blindness-program.

49. Eckert KA, Carter MJ, Lansingh VC, Wilson DA, Furtado JM, Frick KD, Resnikoff S. A Simple Method for Estimating the Economic Cost of Productivity Loss Due to Blindness and Moderate to Severe Visual Impairment. Ophthalmic Epidemiol. 2015;22(5):349-55. doi: 10.3109/09286586.2015.1066394.

50. Sherrod CE, Vitale S, Frick KD, Ramulu PY. Association of Vision Loss and Work Status in the United States. JAMA Ophthalmol. 2014 Oct;132(10):1239-42; quiz 1243-6. doi: 10.1001/ jamaophthalmol.2014.2213.

51. Klein BE. Overview of epidemiologic studies of diabetic retinopathy. Ophthalmic Epidemiol 2007 Jul-Aug;14(4):179-83.

52. Yau JW, Rogers SL, Kawasaki R et al (2012): Global prevalence and major risk factors of diabetic retinopathy. Diabetes Care. 2012 Mar;35(3):556-64. doi: 10.2337/dc11-1909. Epub 2012 Feb 1.

53. Coyne KS, Margolis MK, Kennedy-MartinT, Baker TM, Klein R, Paul MD, et al. The impact of diabetic retinopathy: perspectives from patient focus groups. Fam Pract. 2004 Aug;21(4):447-53.

54. American Geriatrics Society. (2016, December 21). For older adults, poor vision can lead to physical decline and cognitive problems. ScienceDaily. Retrieved April 16, 2020 from www.sciencedaily. com/releases/2016/12/161221091424.htm.

55. Amieva H, Ouvrard C, Meillon C, Rullier L, Dartigues JF. Death, Depression, Disability, and Dementia Associated With Self-reported Hearing Problems: A 25-Year Study. J Gerontol A Biol Sci Med Sci. 2018 Sep 11;73(10):1383-1389. doi: 10.1093/gerona/glx250.

56. Davidson JGS, Guthrie DM. Older Adults With a Combination of Vision and Hearing Impairment Experience Higher Rates of Cognitive Impairment, Functional Dependence, and Worse Outcomes Across a Set of Quality Indicators. J Aging Health. 2019 Jan;31(1):85-108. doi: 10.1177/0898264317723407. Epub 2017 Aug 13.

57. Ramrattan RS, Wolfs RC, Panda-Jonas S, et al. Prevalence and causes of visual field loss in the elderly and associations with impairment in daily functioning: the Rotterdam Study. Arch Ophthalmol. 2001 Dec;119(12):1788-94.

58. Xiang X, Freedman VA, Shah K, Hu RX, Stagg BC, Ehrlich JR. Selfreported Vision Impairment and Subjective Well-being in Older Adults: A Longitudinal Mediation Analysis. J Gerontol A Biol Sci Med Sci. 2020 Feb 14;75(3):589-595. doi: 10.1093/gerona/glz148.

59. Coyne KS, Margolis MK, Kennedy-Martin T, Baker TM, Klein R, Paul M, Revicki DA. The impact of diabetic retinopathy: perspectives from patient focus groups. Fam Pract. 2004 Aug;21(4):447-53.

60. Pronk M, Deeg DJ, Smits C, et al. Prospective effects of hearing status on loneliness and depression in older persons: identification of subgroups. Int J Audiol. 2011 Dec;50(12):887-96. doi: 10.3109/14992027.2011.599871. Epub 2011 Sep 20.

61. Chen DS, Betz J, Yaffe K, et al. Association of hearing impairment with declines in physical functioning and the risk of disability in older adults. J Gerontol A Biol Sci Med Sci. 2015 May;70(5):654-61. doi: 10.1093/gerona/glu207. Epub 2014 Dec 3.

62. Resnick HE, Fries BE, Verbrugge LM. Windows to their world: the effect of sensory impairments on social engagement and activity time in nursing home residents. J Gerontol B Psychol Sci Soc Sci. 1997 May;52(3):S135-44.

63. Gopinath B, Schneider J, Hickson L, et al. Hearing handicap, rather than measured hearing impairment, predicts poorer quality of life over 10 years in older adults. Maturitas. 2012 Jun;72(2):146-51. doi: 10.1016/j.maturitas.2012.03.010. Epub 2012 Apr 20.

64. Kochkin S, Rogin CM. Quantifying the obvious: the impact of hearing instruments on quality of life. Hearing Review. 2000; 7(1):6-34.

65. Rovner BW, Ganguli M. Depression and disability associated with impaired vision: the MoVies Project. J Am Geriatr Soc. 1998 May;46(5):617-9. 
66. Wallhagen MI, Strawbridge WJ, Shema SJ, Kurata J, Kaplan GA. Comparative impact of hearing and vision impairment on subsequent functioning. J Am Geriatr Soc. 2001 Aug;49(8):1086-92.

67. Hetu R, Jones L, Getty L. The impact of acquired hearing impairment on intimate relationships: implications for rehabilitation. Audiology. 1993 Nov-Dec;32(6):363-81.

68. Erdman S, Crowley J, Gillespie G. Considerations in counselling for the hearing impaired. Hear Instrum. 1984;35(11):50-58.

69. Hay-McCutcheon MJ, Reed PE, Cheimariou S. Positive Social Interaction and Hearing Loss in Older Adults Living in Rural and Urban Communities. Journal of Speech Language and Hearing Research, 2018;61(8), 2138. doi.org/10.1044/2018_JSLHR-H-17-0485.

70. Capella-McDonnall ME. The effects of single and dual sensory loss on symptoms of depression in the elderly. Int J Geriatr Psychiatry. 2005 Sep;20(9):855-61.

71. Lin MY, Gutierrez PR, Stone KL, et al. Vision impairment and combined vision and hearing impairment predict cognitive and functional decline in older women. J Am Geriatr Soc. 2004 Dec;52(12):1996-2002.

72. De Jose E. G. Psychological attributes, stressors, and coping of older adults teaching in selected state universities in Manila, Philippines 2014. Paper presented at the International Symposium on Education and Psychology, Meiji University, Tokyo, Japan.

73. Mallari R. Successful Aging and Life Satisfaction of Older Filipinos 2011: Evidence from the Philippine Longitudinal Study on Aging 2007 (Thesis). doi:10.13140/RG.2.2.21445.55523.

74. Coyne KS, Margolis MK, Kennedy-MartinT, Baker TM, Klein R, Paul MD, et al. The impact of diabetic retinopathy: perspectives from patient focus groups. Fam Pract. 2004 Aug;21(4):447-53.

75. World Health Organization Western Pacific Region. Older people's visual impairment: situational analysis of programmes and services in the Philippines [Internet]. 2016 [cited Dec 2019]. Available from https://iris.wpro.who.int/bitstream/handle/10665.1/ 13487/9789290617846-eng.pdf.
76. De la Vega SF. Maximizing the Quality of Life if the Elderly Through Better Health. Jimeno, CA. Prevention and Treatment of Diabetes in Older Individuals. 2006. NAST Monograph Series No. p57-62, ISSN 1655-4299.

77. Genther DJ, Betz J, Pratt S, et al. Association of hearing impairment and mortality in older adults. J Gerontol A Biol Sci Med Sci. 2015 Jan; 70(1): 85-90. Published online 2014 Jul 14. doi: 10.1093/ gerona/glu094.

78. Thiagarajan M, Evans JR, Smeeth L, Wormald RP, Fletcher AE. Cause specific visual impairment and mortality: results from a population based study of older people in the United Kingdom. Arch Ophthalmol. 2005;123(10):1397-1403. doi: 10.1001/archopht. 123.10.1397.

79. Karpa MJ, Gopinath B, Beath K, et al. Associations between hearing impairment and mortality risk in older persons: the Blue Mountains Hearing Study. Ann Epidemiol. 2010;20:452-459. doi: 10.1016/j.annepidem.2010.03.011.

80. Gopinath B, Schneider J, McMahon CM, Burlutsky G, Leeder SR, Mitchell P. Dual sensory impairment in older adults increases the risk of mortality: a population-based study. PLoS One. 2013;8(3): e55054. doi: 10.1371/journal.pone.0055054. Epub 2013 Mar 4.

81. Lam BL, Lee DJ, Gomez-Maron O, Zheng DD, Caban AJ. Concurrent visual and hearing impairment and risk of mortality: the National Health Interview Survey. Arch Ophthalmol. 2006 Jan;124(1):95-101.

82. Schubert CR, Cruickshanks KJ, Fischer ME, Chen Y, Klein BEK, Klein R, Pinto AA. Sensory Impairments and Cognitive Function in Middle-Aged Adults. J Gerontol A Biol Sci Med Sci. 2017 Aug 1;72(8):1087-1090. doi: 10.1093/gerona/glx067.

83. Agrawal N, Kalaivani M, Gupta SK, Misra P, Anand K, Pandav CS. Association of blindness and hearing impairment with mortality in a cohort of elderly persons in a rural area. Indian J Community Med. 2011;36:208-12. doi: 10.4103/0970-0218.86522. 